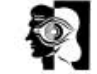

columns organisation of services, and the system of appraisal and accreditation in addiction psychiatry.

The document discusses the prevalence of substance misuse and dependence (addiction), implications for psychiatry and training of specialist addiction psychiatrists. It then discusses specific roles in relation to clinical work, facilitation and liaison, training and education, planning, service development, prevention and policy and, finally, the contribution to research and audit.

The full report is available from the College's Book Sales Office, tel: 0207235 2351 ext. 146.

\section{The Role and Contribution of the Consultant Psychiatrist in Psychotherapy in the NHS}

\section{Council Report CR98 f5.00. 20 pp.}

This position statement has been prepared by the College's Psychotherapy Faculty in order to inform and advise the Department of Health about the specific role and contribution of medically qualified psychotherapists. The key points set out in the statement are summarised below.

The National Service Framework for Mental Health places psychological therapies at the heart of a modern health service. The National Plan is committed to workforce expansion and training.

Consultant psychiatrists in psychotherapy play a pivotal role in both training and delivery of psychological therapies. Their distinctive contribution includes:

- training junior psychiatrists, medical students and other health care professionals in communication skills, supportive psychotherapy and specific psychological techniques of proven effectiveness:

- the capacity to assess and treat complex and severe cases;

- the capacity to combine pharmacotherapy with psychotherapy;

- supervising and supporting psychotherapeutic work in primary care, community mental health teams (CMHTs) and acute in-patient units;

- acting as product champion for psychological therapies among doctors, psychiatrists and the mental health workforce as a whole;

- providing a specific service for people suffering from severe personality disorders and other complex diagnostic groups;

- taking responsible medical officer responsibility for complex cases, participating in 'on-call' rotas and other aspects of the work of the consultant psychiatrist.
They have a 6-year medical training: a 3-year general psychiatric training which includes a mandatory psychotherapy component, and a further 3-year specialist registrar training in psychotherapy. The latter programme equips them with a broad range of expert psychotherapy skills in at least three modalities, and enables them to assess and offer appropriate treatment to complex cases.

Psychological therapies are evidencebased treatments, best organised in a 'tiered' fashion, with simple time-limited treatments delivered in primary care, more difficult cases treated and held in CMHTs and complex cases referred for specialist therapies.

Consultant psychiatrists in psychotherapy work as part of a multi-disciplinary psychological therapies team alongside psychologists, nurses, counsellors, occupational therapists, social workers and 'lay' psychotherapists.

They are few in number and unevenly distributed. Users and carers consistently call for more 'talking treatments'.

'Postcode' variation in provision of psychological therapies is the norm A drive led by the Department of Health to create more consultant psychiatrists in psychotherapy posts will help overcome these gaps and inequalities in provision.

The full report is available from the College's Book Sales Office, tel: 0207235 2351 ext. 146.

\title{
obituaries
}

\section{John Dennis Orme}

Former Consultant Child and Family Psychiatrist, Barnsley District General Hospital

John Orme died on the 7 January 2002 at the age of 81 . A Londoner, he was educated at Highgate School and then went to St Bartholomew's Hospital where he qualified in 1944. Following a very short experience as a casualty officer, he entered the RNVR and spent most of the next 2 years in the Far East. After leaving the Royal Navy, John worked as a general practitioner before becoming medical officer in Bristol mental hospitals, gaining the DPM and MA in Child Psychology during his appointment. John went to Northampton as a senior registrar and subsequently became Consultant Child and Adolescent Psychiatrist in the West Riding and Sheffield in 1956. His responsibilities gradually became concentrated in Barnsley, where he was instrumental in establishing the Pinder Oaks Child Psychiatric Centre. John was elected FRCPsych in 1974 and retired in 1981
John was always much respected by his colleagues and never shunned work in the interest of his patients and their families. He was reserved both in his manner and towards the several novel systems that arose and declined over a quarter of a century. John had the unfashionable but therapeutic knack of helping families to believe that they had achieved successful change by their own efforts.

John is survived by his wife Diana and their two children.

\section{R. A. Bugler}

\section{Elizabeth Joan Harbott}

Former Associate Specialist, Department of Psychiatry, Royal South Hants Hospital, Hampshire

Elizabeth Joan Harbott qualified at the Welsh National School of Medicine in 1957. A post in medicine in Swansea was followed by a period in the Professorial Department of Obstetrics in Cardiff, where she obtained the Diploma in
Obstetrics and Gynaecology. After a short period in general practice, she returned to hospital medicine as a junior house medical officer, before moving to the George Washington Memorial University Hospital in Washington DC as an internal medicine fellow.

On returning to the UK she became a psychiatric trainee, first at Brookwood Hospital and subsequently at St Luke's branch of the Middlesex Psychiatric

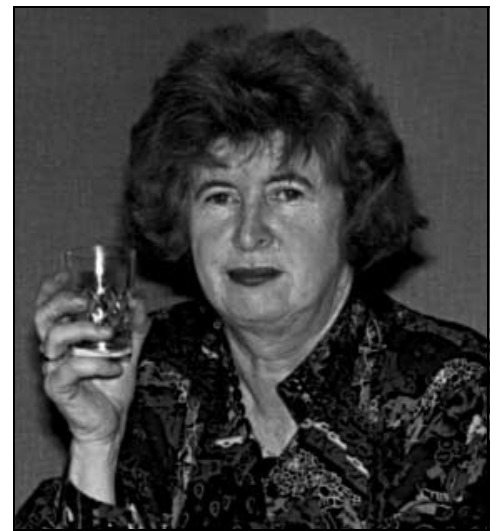


Department, where she met her future husband.

Having obtained the DPM, she and Tony moved to Winchester, where Joan took a part-time staff grade post with the Southampton Psychiatric Service. In 1972, she became a Member of the Royal College of Psychiatrists, but wishing to remain part-time, she continued in a staff grade post, running out-patient and day-patient services.

When the psychiatric services moved from the mental hospital to the city in 1979, Joan became a senior member of the firm dealing with the eastern half of the city. She frequently acted as a part- time locum consultant in a variable and flexible way, making her one of the most valued and discerning members of the Southampton consultant establishment. This unusual career continued without a break until her retirement in 1991, although she did then occasionally return to clinical work in her characteristically helpful way, when she perceived that there were pressures.

Joan's long-standing service in Southampton enabled her to provide continuity of care to a vast number of patients - a virtue which is all too frequently wanting in modern psychiatric practice. Her considerable clinical acumen generated respect from patients and colleagues alike. On many occasions colleagues on her firm would have cause to be grateful for her unusual perspicacity and discernment.

As a colleague she was generous, obliging and unassuming. Outside medicine her interests were wide, including the Welsh language, history, travel, sailing and cooking, to mention only a few.

Joan died on 28 May, 2001, aged 69, following a tragic and short illness, bravely borne.

John Grimshaw

\section{reviews}

\section{Getting the Message Across. Review of Research and Theory about Disseminating Information within the NHS}

By Claire Palmer and Julie Fenner London: Gaskell. 1999. 68 pp. f10.00 (pb). ISBN: 1-901242-36-3

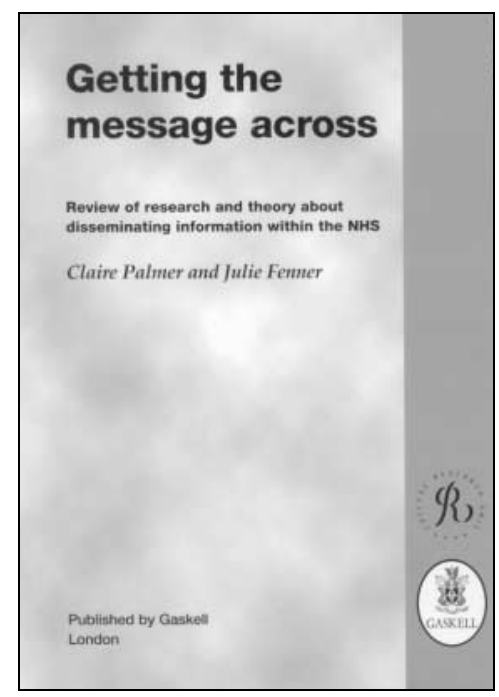

Ultimately the success of evidence-based medicine depends not on the number and quality of trials examining clinical effectiveness but on whether or not the evidence from these trials is implemented in everyday clinical practice. This book offers a good review of the growing literature on dissemination and implementation and as such provides a useful summary of the field. Yet in spite of its comprehensiveness the book is deeply mired in many of the contradictions that beset this area.

No doubt, as the authors claim, the book has many potential readers charged with or involved in dissemination of evidence-based practice. But they will meet the first conundrum in the small warning in the introductory chapter: one must encourage only the dissemination of 'valid and credible' information and 'prevent dissemination of information which has not been properly evaluated'. An obvious point perhaps but like those easy recipes with impossible-to-find ingredients the authors leave unsaid how 'valid and credible' information is to be separated from unevaluated. But more: can we be sure that this book itself falls into the valid category? Well, the review of research evidence quite fairly summarises the existing literature as not having identified successful dissemination strategies. In particular the reader will note that printed materials alone are not of much value, and then perhaps reflect that this book is also 'printed material'.

Having summarised a literature that struggles to identify any dissemination strategy that can claim to work (and change clinicians' behaviour), the authors go on to present a chapter on theories why strategies should work (Chapter 3) and a chapter on how these might be put into practice (Chapter 4). But have the proposals in the latter chapter been shown to work? Do they meet the criteria of being 'valid and credible'? Certainly not by the usual criteria of evidence-based medicine that would look for trial evidence, effect sizes and so on. Indeed, the earlier chapter on existing evidence failed to identify proven dissemination strategies.

So should you buy a 68-page book that commends dissemination strategies that are unevaluated? Ironically the authors' advice seems to be to save your money.

David Armstrong Reader in Sociology as applied to Medicine, Department of General Practice, King's College London

\section{Finding and Keeping. Review of Recruitment and Retention in the Mental Health Workforce}

London: The Sainsbury Centre for Mental Health. 2000. $136 \mathrm{pp}$. f20.00. ISBN: 1-870-480-46-5

On the day that I read the Sainsbury Centre's report on recruitment and retention, the London Evening Standard newspaper contained three separate articles on staff shortages in the NHS. Not that I needed the media to remind me of what has been apparent to mental health workers for several years. As the report confirms, staff vacancies and low morale are contributing to the increasing pressure under which we work.

The report details the staff shortages in various disciplines: $14 \%$ of consultant posts are vacant; $85 \%$ of trusts have difficulty in recruiting and retaining nursing staff; there are similar problems in social work, psychology and occupational therapy. It then makes recommendations that, at a trust level, are aimed at management and human resources. These recommendations are accompanied by an A to $Z$ of practical points, which range from 'advertising' to 'zero tolerance of violence'.

The report highlights the cycle of staffing frustration familiar to those of us who work in an understaffed organisation. Services can be forced into a vicious circle where understaffing or poor retention leads to a heavy workload and low morale for those remaining staff. This results in a further loss of staff and increased recruitment difficulties. The report also reminds readers that the users of such services will suffer. I am sceptical that the practical advice offered is sufficient to address problems in the most severely depleted services. Local initiatives will be ineffective without wider economic and political change. 